\title{
COMPORTAMENTO TÉRMICO DE APARTAMENTOS EM USO DURANTE O INVERNO
}

\author{
Ana Lígia Papst de Abreu, Dra. (IFSC); \\ Camila Ferreira da Silva, graduanda em Eng. Civil (IFSC); \\ Carla Bortolotto Corrêa, graduanda em Eng. Civil (IFSC).
}

PALAVRAS CHAVE

Desempenho térmico; comportamento do usuário; graus hora para aquecimento

KEY WORDS

Thermal performance; user behavior; degree-hour for heating

\section{RESUMO}

Recentes pesquisas usam simulação computacional para analisar os parâmetros físicos da edificação e o comportamento do usuário no desempenho térmico dos ambientes. Este estudo quantifica termicamente como as ações dos ocupantes alteram o desempenho térmico de três apartamentos em uso, na cidade de Florianópolis. O objetivo deste trabalho é demonstrar a variação que ocorre no comportamento térmico do ambiente em função dos ajustes feitos pelo usuário. O método utilizado foi a medição das temperaturas internas durante 28 dias no inverno. O conceito de grau horas para aquecimento foi utilizado para comparar as temperaturas dos três apartamentos em uso com a temperatura de um apartamento vazio. Os resultados mostraram que a diferença nos valores de grau-horas para o aquecimento dos três apartamentos foi entre 32,7\% e 57,3\%. Como conclusão, recomenda-se que as simulações de desempenho térmico incorporem em suas análises as grandes discrepâncias no modo como as pessoas interagem com seu ambiente.

\footnotetext{
ABSTRACT

Recent researches use simulation to analyze the building physical parameters and user behavior in thermal performance of buildings. This study quantifies the influence of the actions of the occupants in the thermal performance of the buildings in three apartments occupied in Florianópolis. The objective of this study is to demonstrate the variation in thermal behavior because of the user settings. The method used was the measurement of internal temperatures for 28 days in the winter. The degree-hours for heating was used to compare the thermal behavior of the three apartments in use with the temperature of an unoccupied apartment. The results showed that the difference in degree-hour for heating of the three apartments was between $32,7 \%$ and $57,3 \%$. In conclusion, it is recommended that the thermal performance simulations incorporate in their analysis the large discrepancies on how people interact with their environment.
} 


\section{INTRODUÇÃO}

Em 2014 (BRASIL, 2015), o setor residencial foi o segundo maior setor que contribuiu para o crescimento da demanda de eletricidade $(5,7 \%)$, ficando atrás apenas do setor comercial (7,4\%). O uso dos edifícios tem forte contribuição na emissão de $\mathrm{CO} 2$ e ao mesmo tempo as edificações são a alternativa mais barata para redução destas emissões. (AGOPYAN e JOHN, 2011).

$O$ consumo total de energia em edificações residenciais é influenciado por diversos fatores, desde o clima, o sistema construtivo, a orientação solar, os equipamentos da edificação, e o comportamento dos ocupantes em suas atividades diárias. Os ocupantes não são receptores passivos do ambiente interno, ao contrário, eles interagem com os sistemas da edificação para melhorar as condições de conforto visual, térmica, acústica e de qualidade do ar (HONG et al., 2015). Sendo que o conforto dos usuários está fortemente relacionado ao consumo de energia (LAMBERTS; DUTRA; PEREIRA, 2014). Com relação à avaliação de conforto térmico, esta é subjetiva, pois lida com sensações térmicas de seres humanos. Por isso, neste artigo não se trabalhará com o conforto térmico, mas com as temperaturas internas dos ambientes ocupados, considerando que os ocupantes alteram as condições internas sempre buscando melhorar a sensação térmica.

O objeto de estudo deste artigo, é o comportamento térmico de ambientes internos ocupados, e esta verificação pode ser feita através de medições in loco ou através de simulações computacionais. As simulações computacionais utilizam modelos matemáticos teóricos ou derivados de dados experimentais, e as vantagens são várias, indo desde a rapidez dos resultados até a possibilidade de análises paramétricas. Mas diferentes softwares analisando o comportamento de uma mesma edificação podem apresentar diferenças nos resultados finais (ABREU, 2004).

As pesquisas de comportamento térmico em edificações residenciais através de simulação computacional têm muitas vantagens frente às pesquisas de coleta de dados em casos reais. Mas como justificativa para este artigo, tem-se que as medições in loco são a representação real do que se estima e se analisa por simulações. Além do que, as medições em casos reais servem para validar as situações resultantes de simulações.

O objetivo deste artigo é demonstrar a variação que ocorre no comportamento térmico do ambiente em função dos ajustes feitos pelo usuário para melhorar a sensação de conforto térmico, e desta forma servir para validar simulações computacionais.

\section{REVISÃO BIBLIOGRÁFICA}

As desvantagens da medição de dados de temperatura em ambientes reais é a necessidade de medições durante um longo período. E muitas vezes estas medições podem ocorrer num período, ou mesmo num ano, onde os dias considerados típicos, não ocorram (ABREU, 2004). As medições de desempenho térmico em locais de trabalho são mais viáveis de serem executadas quando as empresas têm interesse nos resultados (VECCHI, 2015), mas em ambientes residenciais existe um pouco de resistência dos moradores a este tipo de medição.

O desempenho térmico de edificações habitacionais é um dos fatores listados nas exigências dos usuários com relação à habitabilidade na NBR 15.575 (ABNT, 2013). Esta norma estabelece dois procedimentos para avaliação da adequação das edificações com relação ao desempenho térmico. $O$ primeiro procedimento é através da verificação do atendimento dos sistemas construtivos de vedações verticais e coberturas aos critérios estabelecidos de transmitância térmica e capacidade térmica, e se estes não forem atendidos, a avaliação deve ser feita através de simulação computacional. A NBR 15.575 apresenta valores mínimos de transmitância térmica e de capacidade térmica de coberturas e vedações verticais, como procedimento de verificação de atendimento aos requisitos mínimos de desempenho térmico. $O$ segundo procedimento para verificação do desempenho térmico é através de medições de temperaturas em edificações ou protótipos em tamanho real. Na NBR 15.575 (ABNT, 2013) a avaliação do desempenho térmico da edificação por medição deve ser feita num dia típico de projeto (verão e inverno), que é caracterizado unicamente pelos valores da temperatura do ar. Um dia típico de verão em Florianópolis tem temperatura máxima diária de $32,7^{\circ} \mathrm{C}$ e amplitude de $6,6^{\circ} \mathrm{C}$, e um dia típico de inverno tem temperatura mínima diária de $6,0^{\circ} \mathrm{C}$ e amplitude diária de $7,4^{\circ} \mathrm{C}$. No verão, para a edificação ser considerada com um desempenho térmico "Mínimo", a temperatura interna máxima nos ambientes de permanência prolongada (salas e dormitórios) tem de ser inferior a temperatura externa máxima. Para um desempenho térmico "Mínimo" de inverno, os ambientes de permanência prolongada têm de apresentar temperatura interna mínima $3^{\circ} \mathrm{C}$ acima da temperatura mínima externa.

As medições das condições térmicas em ambientes podem ser feitas em ambientes em uso ou desocupados. Mas nos ambientes desocupados não se demonstra os ajustes que os usuários fazem para melhorar a sua sensação de conforto (PAPST, 2004). No texto da NBR 15.575 não é feita nenhuma referência aos ambientes estarem ou não sendo ocupados. 
As simulações computacionais mostram que as ações dos usuários, em função do desempenho térmico da edificação e da sua sensação térmica, tem forte impacto no consumo de energia. (BONTE; THELLIER; LARTIGUE, 2014).

Atualmente, as simulações computacionais são usadas mais do que simplesmente estimar o consumo e comportamento térmico de uma edificação, são usadas também para identificar os parâmetros mais dominantes no comportamento térmico, e atribuir a incerteza a este parâmetro (IEA, 2013). A simulação computacional também está sendo usada para estimar a discrepância devida ao comportamento dos ocupantes. (BONTE; THELLIER; LARTIGUE, 2014; SILVA e GHISI, 2014; VIROTE e NEVES-SILVA, 2012). Usualmente, o comportamento dos usuários utilizados em simulações é baseado em premissas estabelecidas pela pesquisa, e não baseada em observações ou métodos estimativos a partir de medições reais.

Silva e Ghisi (2014), através de simulação, determinaram a incerteza do desempenho térmico e do consumo de energia numa edificação residencial em função dos parâmetros físicos da construção e do comportamento do usuário. Foram simulados 2080 casos, para diferentes variações paramétricas dos aspectos físicos da edificação e do comportamento do usuário. Para a análise do desempenho térmico da edificação, os autores usaram tanto o conceito de graus hora para aquecimento e para resfriamento, quanto o consumo de energia do ar condicionado. Na simulação para cálculo dos graus hora para aquecimento e resfriamento, considerou-se que a edificação só usava ventilação natural. Para cálculo dos graus hora para aquecimento utilizou-se como base a temperatura de $19^{\circ} \mathrm{C}$, e para resfriamento a temperatura de $26^{\circ} \mathrm{C}$. Uma das conclusões que chegaram, é que utilizando o somatório de graus hora de aquecimento, a incerteza é superior a 17,2\% para os parâmetros físicos da edificação, e de 21,5\% para os parâmetros de comportamento dos usuários. Para o somatório de graus hora de resfriamento, obteve-se $15,2 \%$ de incerteza para os parâmetros físicos da edificação e de 6,6\% para os parâmetros de comportamento dos usuários. Desta forma, observa-se que as maiores incertezas ocorrem com relação ao comportamento dos usuários nos períodos frios, quando é necessário o aquecimento.

\section{MATERIAIS E MÉTODOS}

As simulações computacionais mostram que as ações dos usuários, em função da sua sensação térmica, tem forte impacto no desempenho térmico da edificação. Para poder comparar a variação térmica interna, tendo como foco o com- portamento dos usuários de edificações residenciais em uso, buscou-se minimizar os impactos das variáveis construtivas e climáticas. Assim, as medições foram feitas todas no mesmo período, buscou-se a tipologia de edifício multifamiliar para se trabalhar com apartamentos de mesma planta (apesar de terem orientações solares diferentes), e apartamentos que não fossem no último pavimento (evitar a carga térmica advinda pela cobertura) ou no pavimento térreo (evitar a possibilidade de perda de calor pelo contato da laje com o solo). Os apartamentos monitorados fazem parte de dois condomínios com a mesma planta do pavimento tipo, e estão localizados no mesmo micro-clima de Florianópolis. As medições foram feitas nos apartamentos onde os proprietários concordaram em participar da pesquisa. A seguir é feita uma descrição dos apartamentos, após como foram feitas as aquisições de temperaturas, e finalmente os critérios adotados para a análise e comparação dos dados.

\subsection{Descrição dos apartamentos monitorados}

Os apartamentos monitorados não pertencem todos ao mesmo bloco e não estão localizados todos mesmo andar. As limitações desta pesquisa nesta etapa são duas: os apartamentos e ou ambientes têm diferentes orientações solares; e o sombreamento do entorno é parecido, mas não idêntico. As características de aberturas e vedações verticais (paredes) são as mesmas. A Figura 1 demonstra as características térmicas dos fechamentos verticais opacos, que atende aos requisitos da NBR 15.575 para Florianópolis.

Figura 01: Croqui da vedação vertical com suas características de transmitância e de capacidade térmica

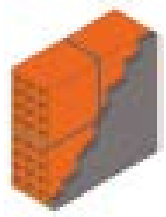

Transmitância térmica: $1,97 \mathrm{~W} / \mathrm{m}^{2} \mathrm{~K}$

Capacidade térmica: $151,67 \mathrm{~kJ} / \mathrm{m}^{2} \mathrm{~K}$

Fonte:Autores

As medições foram feitas em três apartamentos em uso e um apartamento desocupado, que serviu de referência. Mas como o apartamento desocupado estava à venda, este não permaneceu fechado durante todo o período da medição. Ocorreram visitas esporádicas de corretores de imóveis com interessados no imóvel.

A Figura 2 mostra a localização dos apartamentos nos quatro blocos que fazem parte do condomínio analisado, a orientação solar dos apartamentos, e também os critérios de designação dado aos apartamentos (A, B, C e V para o aparamento vazio, desocupado). Os apartamentos são todos de canto. 
Figura 02: Croqui de localização dos apartamentos nos edifícios

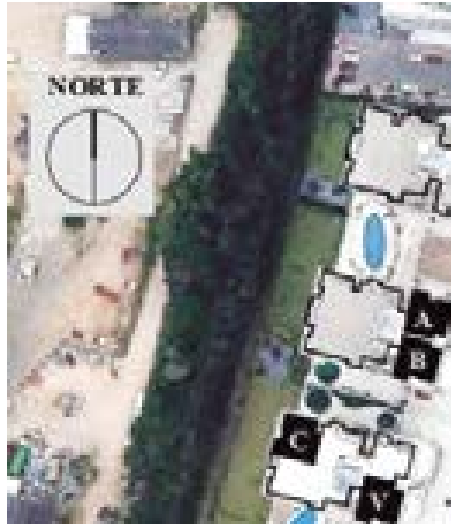

Fonte: Imagem Google Earth adaptada pelos Autores

Na Figura 3 apresenta-se a planta de um dos apartamentos, onde se verifica que a suíte e a sala (ambientes monitorados) têm as aberturas na mesma orientação solar. Mas a suíte tem vedações verticais em duas orientações solares diferentes.

Figura 03: Croqui da planta do apartamento tipo.

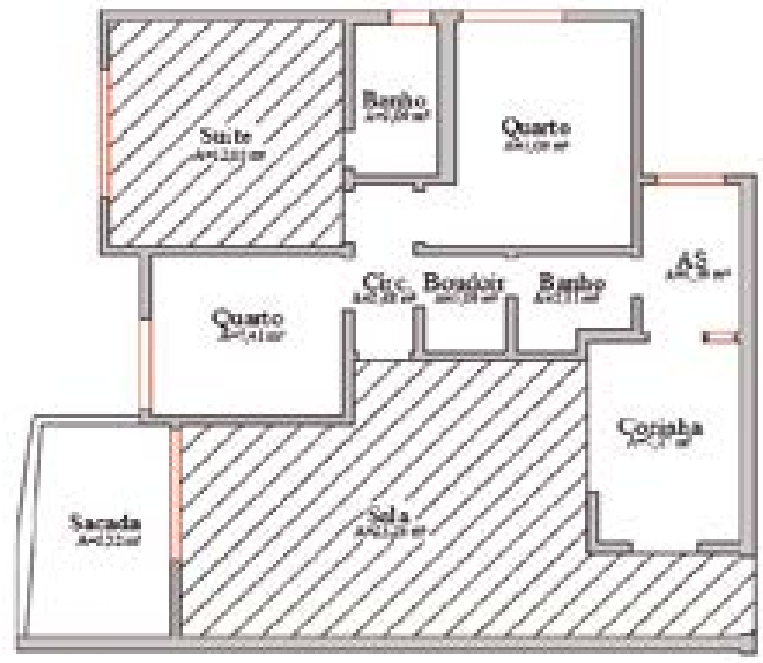

Fonte: elaborado pelos autores a partir de dados fornecidos pela construtora

Com exceção do apartamento desocupado, todos os apartamentos possuem condicionador de ar quente e frio na sala e na suíte, e não se teve controle de se estes equipamentos foram acionados durante o período das medições.

\subsection{Medição das temperaturas}

Para a aquisição dos dados de temperatura foram utilizados quatro modelos diferentes de aquisição de dados (data loggers) da Onset Corporation (Tabela 1), e os dados coletados foram transferidos pelo software próprio do equipamento
(HOBOware) a um computador pessoal, para posterior análise.

Tabela 01: Descrição dos sistemas de aquisição utilizados para medição das temperaturas

\begin{tabular}{|c|c|c|c|}
\hline $\begin{array}{l}\text { Morblo } \\
\text { Hoeo: } \\
\text { Temp RH } \\
\text { U12-011 }\end{array}$ & $\begin{array}{l}\text { Imingem } \\
= \\
=\end{array}$ & $\begin{array}{l}\text { Faixa do } \\
\text { mediç̨äo } \\
-20^{\circ} \mathrm{Ca} \\
10^{\circ} \mathrm{C}\end{array}$ & $\begin{array}{l}\text { Acurkis is } \\
\pm 035^{\circ} \mathrm{C}\end{array}$ \\
\hline $\begin{array}{l}\text { HOBO" } \\
\text { Temp/RH } \\
\text { UXico cos }\end{array}$ & 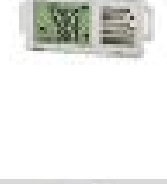 & $\begin{array}{c}-20^{\circ} \mathrm{C} \text { a } \\
10 \mathrm{C}^{\circ}\end{array}$ & $\pm 0.21 \mathrm{C}$ \\
\hline $\begin{array}{l}\text { IOOR: Pno } \\
v_{2} \\
123-\infty 1\end{array}$ & ind & $\begin{array}{l}\text { Aor a } \\
70 C^{\circ}\end{array}$ & $1021 \mathrm{r}$ \\
\hline $\begin{array}{l}\text { HOBO" } \\
\text { Peridant" } \\
\text { Templight } \\
\text { UA-0020s }\end{array}$ & $\begin{array}{l}E \\
301 \\
304\end{array}$ & $\begin{array}{c}-20^{\circ} \mathrm{Ca} \\
70 \mathrm{t}\end{array}$ & $\pm 053^{\circ}$ \\
\hline
\end{tabular}

Fonte: Elaborado pelos autores a partir dos manuais dos equipamentos

Para a medição das temperaturas externas foi utilizado o modelo U23-001, ideal para ambiente externo, e colocado na sacada do Apartamento $C$. Os outros equipamentos foram dispostos sobre móveis de madeira, buscando sempre a centralidade dos ambientes e evitando serem colocados próximos a paredes que tenham contato com o exterior.

A aquisição de dados das temperaturas (salas, suítes e ambiente externo) foi feita de quinze em quinze minutos, durante os dias 08 de julho e 04 de agosto de 2015, e posteriormente feita a média hora a hora numa planilha do Excel. Também foram feitas as médias das temperaturas diárias, verificada a temperatura máxima e mínima diária, tanto dos ambientes internos, quanto do ambiente externo.

\subsection{Critérios para comparação do comporta- mento térmico}

Para uma primeira caracterização do comportamento térmico dos ambientes internos com relação à temperatura externa, os dados de temperatura medidos internamente e 
externamente são apresentados em gráficos com a temperatura média diária, temperatura máxima diária e temperatura mínima diária.

O critério de somatório de graus hora $\left(\Sigma^{\circ} \mathrm{C} . h\right)$ para aquecimento foi utilizado para comparar os ambientes internos ocupados com os ambientes do apartamento desocupado e também com o ambiente externo. $\mathrm{O}$ somatório de graus hora para aquecimento é determinado usando-se uma temperatura base, onde se faz o somatório de graus que estejam abaixo deste limite estipulado (Figura 4). As temperaturas base para análise nesta pesquisa foram de $19^{\circ} \mathrm{C}$ e $21^{\circ} \mathrm{C}$.

Figura 4: Exemplo de Somatório de graus hora de aquecimento

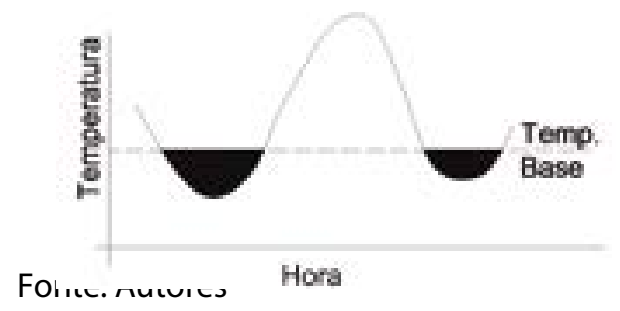

\section{RESULTADOS}

Na Figura 5, as temperaturas máximas, médias e mínimas dos ambientes internos (apartamentos em uso e desocupado) são apresentadas sobre as temperaturas máximas, médias e mínimas do ambiente externo.

Apesar das medições terem ocorrido nos meses de julho e início de agosto, não ocorreu nenhum dia típico de inverno (ABNT, 2013), com temperatura mínima diária de $6,0^{\circ} \mathrm{C}$ e amplitude diária de $7,4^{\circ} \mathrm{C}$. Utilizando o critério de desempenho térmico "Mínimo" de inverno da NBR 15.575, os ambientes de permanência prolongada em Florianópolis têm de apresentar temperatura interna mínima $3^{\circ} \mathrm{C}$ acima da temperatura mínima externa, ou seja, superior a $9^{\circ} \mathrm{C}$. Como a menor temperatura externa do período de 28 dias de monitoramento foi de $16,7^{\circ} \mathrm{C}$, com amplitude de $2,4^{\circ} \mathrm{C}$, não ocorreram dias com temperaturas baixas para esta análise. O que se observa é que todas as temperaturas internas mínimas foram superiores ao preconizado pela NBR 15.575 como desempenho térmico Mínimo $\left(9^{\circ} \mathrm{C}\right)$. Comparando a diferença da temperatura mínima externa com a mínima interna da sala, a diferença no apartamento vazio foi entre $1^{\circ} \mathrm{C}$ e $3^{\circ} \mathrm{C}$ acima, sendo que nas salas dos apartamentos ocupados a diferença das temperaturas mínimas variou entre $1,3^{\circ} \mathrm{C}$ no apartamento $\mathrm{B}$, até $5^{\circ} \mathrm{C}$ no apartamento A. Para a temperatura mínima externa comparada com a mínima interna nas suítes, a diferença foi menor, no apartamento desocupado os valores variaram entre $0,3^{\circ} \mathrm{C}$ e $2^{\circ} \mathrm{C}$, e nas suítes dos apartamentos ocupados foi entre $1,1^{\circ} \mathrm{C}$ (apartamento $\mathrm{C}$ ) e $3,8^{\circ} \mathrm{C}$ (apartamento $\mathrm{A}$ ).

A Tabela 2 apresenta o somatório de graus hora $\left(\Sigma^{\circ} \mathrm{C} . h\right)$ para aquecimento de todos os ambientes internos e do ambiente externo, tendo como base $19^{\circ} \mathrm{C}$ e $21^{\circ} \mathrm{C}$. Através da análise da Tabela 2, observa-se que todos os ambientes internos apresentaram graus hora inferiores ao ambiente externo, tanto para temperatura base de $19^{\circ} \mathrm{C}$ quanto $21^{\circ} \mathrm{C}$. Em função do que se observou de comportamento térmico das temperaturas mínimas internas, o somatório de graus hora de aquecimento dos ambientes suítes foram superiores ao somatório de graus hora de aquecimento dos ambientes salas. Isto possivelmente se deve aos ganhos de calor advindos da cocção. O somatório de graus hora tendo como base $19^{\circ} \mathrm{C}$, não apresentou valores para os ambientes das salas dos apartamentos, e para a suíte do apartamento $A$, que tem abertura para Norte, e parede externa a leste. Possivelmente os ganhos térmicos solares das primeiras horas do dia fizeram com que este ambiente não apresentasse temperaturas inferiores a $19^{\circ} \mathrm{C}$, visto que a moradora relatou que minimiza ao máximo o uso do condicionamento de ar, e o utiliza mais para resfriamento do que aquecimento.

As comparações dos valores de graus hora são feitas a seguir em duas partes, uma primeira com relação ao ambiente externo, e outra com relação ao apartamento desocupado.

Comparando com o ambiente externo, o somatório de graus hora de aquecimento da sala do apartamento desocupado, tendo como base $21^{\circ} \mathrm{C}$, foi em torno de $40 \%$ do valor do somatório de graus hora externo, e na suíte $76 \%$ do valor dos graus hora de aquecimento do ambiente externo. Nos apartamentos ocupados, os percentuais de graus hora de aquecimento internos comparados com o externo variaram nas salas entre 1,8\% e 5,5\%. Nas suítes dos apartamentos ocupados, esta variação foi entre $22,1 \%$ e $38,5 \%$. 
Figura 5: Gráficos das distribuições das temperaturas mínimas, médias e máximas internas dos oito ambientes monitorados sobre as temperaturas mínimas, médias e máximas externas

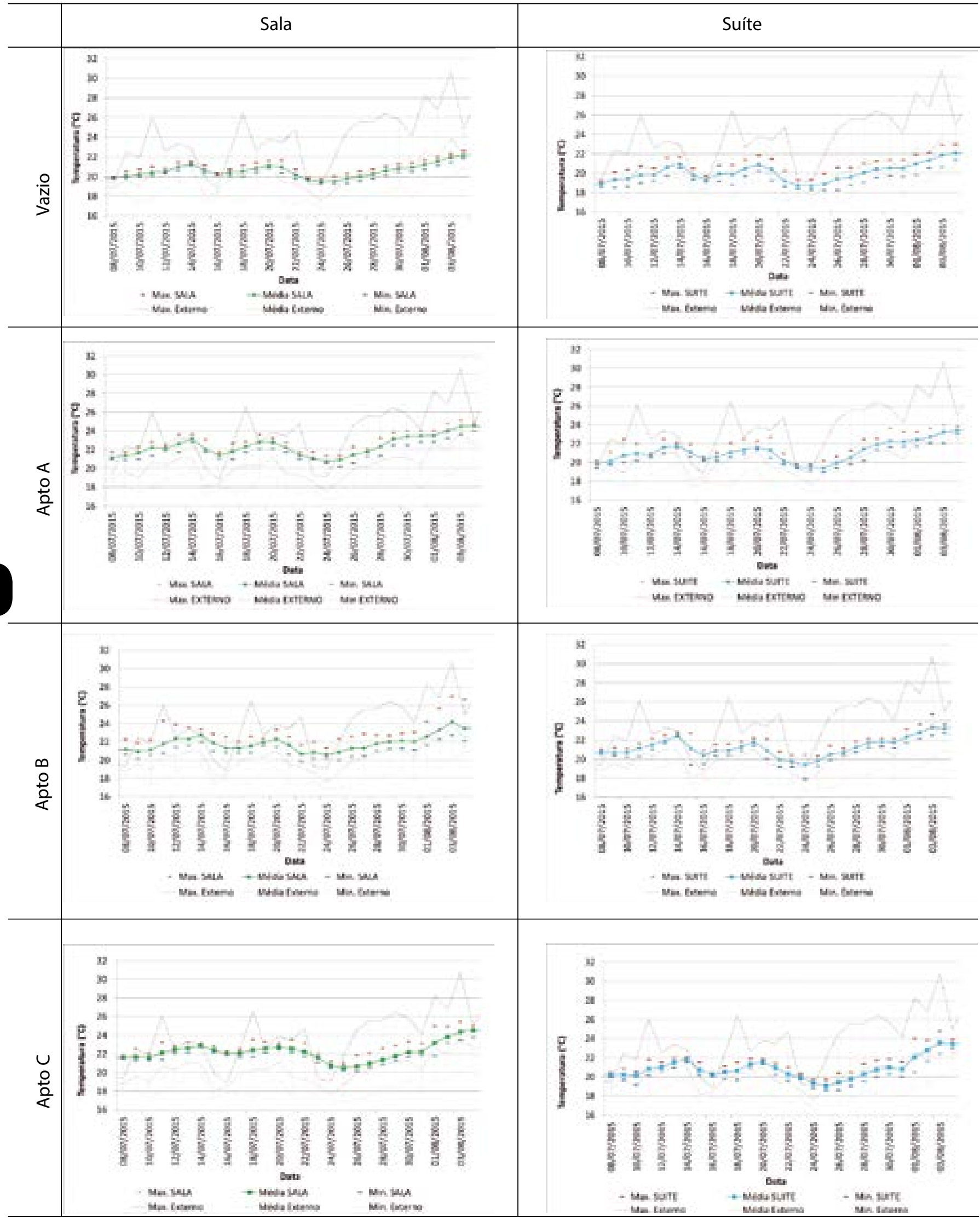


Tabela 2: Somatório do grau hora para temperaturas menores que $19^{\circ} \mathrm{C}$ e $21^{\circ} \mathrm{C}$

\begin{tabular}{|c|c|c|c|c|c|c|c|c|c|}
\hline & \multirow[t]{2}{*}{ Externo } & \multicolumn{2}{|c|}{$\begin{array}{l}\text { Apartamento } \\
\text { Vazio }\end{array}$} & \multicolumn{2}{|c|}{ Apartamento A } & \multicolumn{2}{|c|}{ Apartamento B } & \multicolumn{2}{|c|}{ Apartamento $\mathrm{C}$} \\
\hline & & Sala & Suite & Sala & Suite & Sala & Suite & Sala & Suite \\
\hline$\Sigma^{\circ} \mathrm{Ch}<19^{\circ} \mathrm{C}$ & 204.2 & 0.0 & 35,7 & 0.0 & 0.0 & 0.0 & 4.9 & 0,0 & 6.1 \\
\hline$\Sigma^{\circ} \mathrm{C} h<21^{\circ} \mathrm{C}$ & 936.1 & 372,8 & 709,1 & 16,7 & 270,2 & 51,1 & 206.9 & 32.3 & 360,7 \\
\hline
\end{tabular}

Fonte: Autores

Quando se relaciona o somatório de graus hora de aquecimento dos apartamentos em uso com o apartamento desocupado para a temperatura base de $21^{\circ} \mathrm{C}$, observa-se que na sala, os apartamentos ocupados apresentaram menor relação. $O$ somatório de graus hora de aquecimento da Sala do Apartamento A, foi somente 4,5\% do somatório de graus hora de aquecimento do apartamento desocupado, e esta percentagem foi de $13,7 \%$ na sala do apartamento $B$, e de $8,7 \%$ na sala do apartamento C. Já nas suítes, o somatório de graus hora de aquecimento apresentou valores maiores, e a porcentagem da relação de graus hora de aquecimento da suíte do apartamento desocupado com os graus hora de aquecimento das suítes dos apartamentos em uso, também aumentou. A suíte do apartamento $A$ apresentou valor de graus hora de aquecimento $38,1 \%$ em relação ao apartamento desocupado, e estes valores foram $29,2 \%$ para a suíte do apartamento $B$ e $50,9 \%$ para a suíte do apartamento $C$.

Comparando os somatórios de graus hora de aquecimento entre os apartamentos ocupados entre si, com relação à base de $21^{\circ} \mathrm{C}$, encontra-se uma diferença de $32,7 \%$ nos valores das salas (apartamentos A e B), e de $57,3 \%$ nos valores das suítes (apartamentos $B$ e $C$ ).

\section{CONSIDERAÇÕES FINAIS}

As simulações computacionais tem a grande vantagem de analisar diversos cenários de uso, tipos de edificações, climas, entre outros, que em medições reais se tornariam muito difíceis de serem replicadas. Silva e Ghisi (2014) mostraram através de simulação computacional que as maiores incertezas, nos critérios por eles analisados, ocorreram com relação ao comportamento dos usuários nos períodos frios, mais do que a incerteza dos parâmetros físicos da edificação.

As comparações do somatório de graus hora de aquecimento dos ambientes do apartamento desocupado com relação ao somatório de graus hora de aquecimento do ambiente externo, foram entre $40 \%$ e $76 \%$, enquanto nos apartamentos ocupados esta relação com os graus hora de aquecimento do ambiente externo foi entre 1,8\% e 38,5\%. Relacionando os graus hora de aquecimento dos apartamentos ocupados com o apartamento desocupado, o ambiente da sala é que apresentou menor relação, e nas suítes a relação de graus hora de aquecimento chegou a ser de 50,9\%. Isto ocorreu possivelmente pelos ganhos internos de calor da sala e a forma de ocupação do apartamento.

Quando os somatórios de graus hora são comparados somente entre ambientes em uso, obtêm-se variações de até $57,3 \%$. Este valor obtido através de medições reais, com uma pequena amostra de apartamentos, demonstra que as simulações computacionais de desempenho térmico precisam considerar as grandes discrepâncias no modo como as pessoas interagem com seu ambiente residencial.

\section{REFERÊNCIAS}

1. ABNT - ASSOCIAÇÃO BRASILEIRA DE NORMAS TÉCNICAS. NBR 15.575-1: Edificações Habitacionais - Desempenho parte 1: requisitos gerais. Rio de Janeiro: ABNT, 2013.

2. ABREU, A.L.P. Método Estimativo da Temperatura Interna de Edificações Residenciais em Uso. 2004. 179p. Tese (Doutorado) - Programa de Pós-Graduação em Engenharia Civil, Centro Tecnológico, Universidade Federal de Santa Catarina. Florianópolis, 2004.

3. AGOPYAN, $V_{;} ; J O H N, V_{\text {.M. }}$ O desafio da Sustentabilidade na Construção Civil. São Paulo: Blucher, 2011.

4. BONTE, B.; THELLIER, F; ;ARTIGUE, B. Impact of occupant's actions on energy building performance and thermal sensation. Energy and Buildings. v. 76, p. 219-227, jun. 2014.

BRASIL. Empresa de Pesquisa Energética. Balanço Energético Nacional 2015: ano-base 2014. Relatório Síntese. Rio de Janeiro: EPE, 2015.

5. HONG, T. et al. An ontology to represent energy-related occupant behavior in buildings. Part I: Introducion to the DNAs framework. Building and Environment, v. 92, p. 764-777, out. 2015. 
International Energy Agency (IEA), Energy in Buildings and Communities Programme (EBC) Annex 53 - Total Energy Use in Buildings, Analysis and Evalution Methods, Final Report IEA, 2013.

6. LAMBERTS, R.; DUTRA, L.; PEREIRA, F.O.R. Eficiência Energética na Arquitetura. 3 ed. Rio de Janeiro: Eletrobras/Procel, 2014.

7. SILVA, A.S.; GHISI, E. Uncertainty analysis of user behavior and physical parameters in residential buildings performance simulantion. Energy and Buildngs. v. 76, p. 381-391, jun. 2014.

8. VECCHI, R. Avaliação de conforto térmico em edificações comerciais que operam sob sistemas mistos de condicionamento ambiental em clima temperado e úmido. 2015. Tese (Doutorado) - Programa de Pós-Graduação em Engenharia Civil, Centro Tecnológico, Universidade Federal de Santa Catarina. Florianópolis, 2015.

9. VIROTE, J.; NEVES-SILVA, R. S tochastic models for building energy prediction based on occupant behavior assessment. Energy and Buildings. v. 53, 183-193, out. 2012.

\section{AGRADECIMENTOS}

Ao CNPq pelas bolsas acadêmicas, ao IFSC pelos recursos disponibilizados ao projeto, ao LabEEE / UFSC pelo empréstimo de parte dos equipamentos utilizados, a construtora Cota que nos auxiliou de diversas formas, mas principalmente nos colocou em contato com os moradores e nos disponibilizou o apartamento vazio. Eprincipalmente, aos moradores dos apartamentos que tão gentilmente nos possibilitaram fazer as medições em seus lares. 